\title{
VHDL Implementation of Robust Wi-Fi Positioning System
}

\author{
Lingaraj Duggani \\ Dept. of TCE KLEDRMSSCET, \\ Belagavi, Karnataka, India \\ Affiliated to VTU, Belagavi
}

\author{
Udaykumar L. Naik, PhD \\ Dept. of TCE KLEDRMSSCET, \\ Belagavi, Karnataka, India \\ Affiliated to VTU, Belagavi
}

\author{
Vijay Rayar \\ Dept. of ECE \\ KLEDRMSSCET, \\ Belagavi, Karnataka, India \\ Affiliated to VTU, Belagavi
}

\begin{abstract}
Design of a cost effective and accurate positioning of a wireless device is one of the challenging issues in Wireless Local Area Networks (WLANs). In this paper we present a novel positioning system by utilizing WLAN received signal strength measurements. The technique includes two parts; First, distance estimation using received signal strength indication (RSSI) using polynomial fitting method. Second, simplified and accurate geometric location algorithm (GLA) is proposed. The proposed technique is less complex and easy to implement. The technique not requires any extra hardware and offline training.

This location algorithm is designed and tested in MATLAB tool and described using Very high speed integrated circuit Hardware Description Language (VHDL), synthesized in XILINX ISE 10.1 and simulated in ISE simulator. Novelty of the HDL description is that, IEEE754 floating point representation is used, which increases the accuracy.
\end{abstract}

\section{Keywords}

RSSI, WLAN, GLA, Positioning, VHDL, IEEE-754

\section{INTRODUCTION}

Positioning of objects and humans in both indoor and outdoor environment has become a more challenging research topic now a day, due to the improvements in the wireless communication technology. Global positioning system (GPS) is the most suitable for outdoor environment [1], as it is efficient, low cost and provides scalable positioning service. However using GPS scheme the signals received from the satellites are not efficient to calculate the indoor positioning of the objects.

Various accepted distance estimation methods in use are time of arrival (TOA) [4], time difference of arrival (TDOA) [5], angle of arrival (AOA) [6], and received signal strength indicator (RSSI) [14]. The synchronization requirement between transmitter and receiving nodes in TOA and TDOA, direction of radio waves calculation in AOA requires extra hardware. However, RSSI based mathematical models are less complex.

In this paper, first, RSSI based polynomial fitting algorithm [3] is used to calculate the distance between the base station (BS) and the mobile station (MS) and, second, geometric location algorithm [2] is used to locate the object. Calculation of this algorithm is done at the MS (mobile-based schemes). MS is equipped with battery. Conventional algorithm uses lot of computations hence energy. But, this geometric location algorithm reduces the computations carried out at the MS to reduce the power consumption. And also it is showed that this algorithm is accurate [2]. The main objective of our approach is to improve positioning accuracy and simplified calculations at the MS in the positioning process.

In this paper, section II describes related work. Section III describes the methodology of proposed design which includes polynomial fitting algorithm and geometric location technique. In section IV how proposed design is designed in IEEE-754 floating point representation is given. Finally results and conclusions are given in section $\mathrm{V}$ and VI respectively.

\section{RELATED WORK}

Various positioning estimation methods have been proposed to find the location of the MS using various parameters such as time of arrival (TOA) [4], time difference of arrival (TDOA) [5], angle of arrival (AOA) [6] and received signal strength (RSS) [14].

RSSI based distance estimation methods are becoming more popular because of simple and low cost. Geometric location algorithms are simple and accurate. There are many propagation models to describe indoor positioning system [7], Okumura model is applicable in large urban area but it respond slowly to the sudden changes in the terrain [8]. Hata model [9] uses graphical path loss data obtained by Okumura. It works well in the current cellular system but not suits indoor environment. Extension to the Hata model is COST231 model [7] ; it is suitable for urban, suburban and rural area. But diffractions from rooftops and buildings are not considered by this model. Egli's propagation model is simple and it assumes terrain with hill of approximately 50 feet height. But this is limited to flat surfaces [10]. In this paper we used polynomial fitting method to estimate the distance between AP and MS.

Positioning calculation can be done either at MS or BS. But positioning in BS involves high cost and low accuracy [11]. Hence, we go for MS based positioning. In this paper we used geometric location algorithm to estimate the position of MS because minimum instructions are used, these instructions are simple and can be easily executed at MS. Main motivation for this paper is low cost, simple and high accuracy.

\section{METHODOLOGY}

\subsection{Design flow}

Flow chart of the proposed localization algorithm is shown in Fig.1 


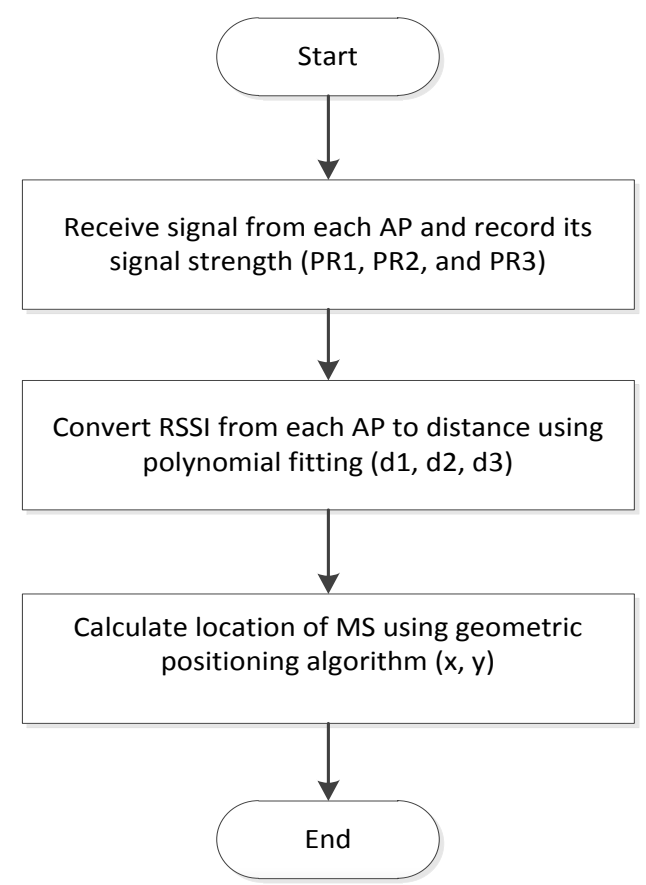

Figure 1. Design flow

\subsection{Geometric location algorithm (gla)}

GLA used here requires three APs. Consider that range circle of all three APs intersect at single point as shown in Fig.2

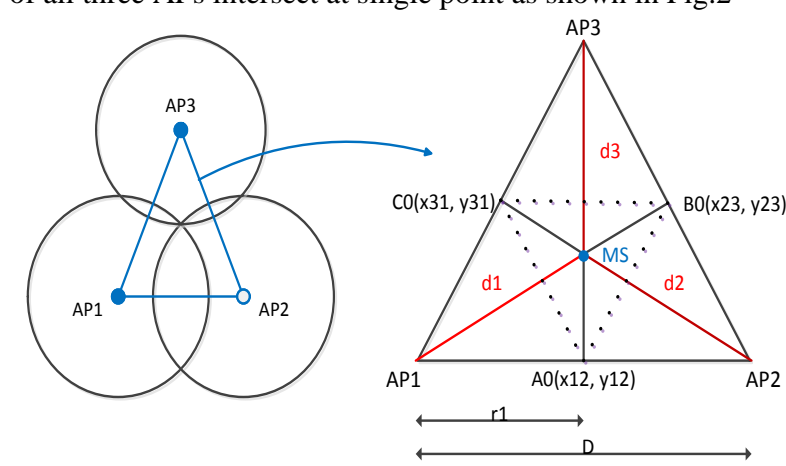

Figure 2. Intersection of three circles and associated triangles

Where,

$\mathrm{D}$, The distance between any two APs

$\mathrm{A} 0, \mathrm{~B} 0$ and $\mathrm{C} 0$ are the orthogonal projections of the $\mathrm{MS}$ on $\left(\mathrm{AP}_{1}, \mathrm{AP}_{2}\right),\left(\mathrm{AP}_{2}, \mathrm{AP}_{3}\right)$ and $\left(\mathrm{AP}_{2}, \mathrm{AP}_{1}\right)$ respectively

$d_{1}, d_{2}$ and $d_{3}$ are the distances between the MS and $A P_{1}, A P_{2}$ and $\mathrm{AP}_{3}$ respectively calculated by the RSSI received from each APs which is given in next section

Some assumptions are made in the GLA [2]. First, All three APs are placed at each corner of the equilateral triangle. Hence, distances between any two APs are same. Second, coordinates of APs are initially known to MS. Third, Now MS can be placed anywhere inside the triangle.

Distance between $\mathrm{AP}_{1} \mathrm{AP}_{2}, \mathrm{AP}_{2} \mathrm{AP}_{3}$ and $\mathrm{AP}_{3} \mathrm{AP}_{1}$ are calculated as below

$\mathrm{D}_{1}=\sqrt{\left(\mathrm{X}_{1}-\mathrm{X}_{2}\right)^{2}+\left(\mathrm{Y}_{1}-\mathrm{Y}_{2}\right)^{2}}$

$\mathrm{D}_{2}=\sqrt{\left(\mathrm{X}_{2}-\mathrm{X}_{3}\right)^{2}+\left(\mathrm{Y}_{2}-\mathrm{Y}_{3}\right)^{2}}$
$\mathrm{D}_{3}=\sqrt{\left(\mathrm{X}_{3}-\mathrm{X}_{1}\right)^{2}+\left(\mathrm{Y}_{3}-\mathrm{Y}_{1}\right)^{2}}$

Distance between $\mathrm{AP}_{1}$ and orthogonal projection of $\mathrm{MS}$ on $\mathrm{AP}_{1} \mathrm{AP}_{2}$ is $\mathrm{r} 1$ and it is given in [12] as,

$r_{1}=\frac{D_{1}^{2}+d_{1}^{2}-d_{2}^{2}}{2 D_{1}}$

And one intermediate factor $\mathrm{q}_{1}$ is defined as

$$
q_{1}=\frac{r_{1}}{D_{1}}=\frac{D_{1}^{2}+d_{1}^{2}-d_{2}^{2}}{2 D_{1}^{2}}
$$

Using this $\mathrm{q} 1$, coordinate of point $\mathrm{A} 0$ i.e., $\left(\mathrm{x}_{12}, \mathrm{y}_{12},\right)$ are given by [12] as

$\left.\begin{array}{l}x_{12}=q_{2} X_{2}+\left(1-q_{1}\right) X_{1} \\ y_{12}=q_{2} Y_{2}+\left(1-q_{1}\right) Y_{1}\end{array}\right\}$

Where $\left(\mathrm{X}_{1}, \mathrm{Y}_{1}\right)$ and $\left(\mathrm{X}_{2}, \mathrm{Y}_{2}\right)$ are coordinates of $\mathrm{AP}_{1}$ and $\mathrm{AP}_{2}$ respectively. Similarly $\left(\mathrm{x}_{23}, \mathrm{y}_{23},\right)$ and $\left(\mathrm{x}_{31}, \mathrm{y}_{31},\right)$ are calculated as shown in [12]

Now new virtual APs are placed at A0, B0 and C0. Distance between MS and these A0, B0 and $\mathrm{C} 0$ are calculated using Pythagoras formula as shown below

$\left.\begin{array}{l}d_{1}\left(M S, A_{0}\right)=\sqrt{d_{1}^{2}-r_{1}^{2}} \\ d_{2}\left(M S, B_{0}\right)=\sqrt{d_{2}^{2}-r_{2}^{2}} \\ d_{3}\left(M S, C_{0}\right)=\sqrt{d_{3}^{2}-r_{3}^{2}}\end{array}\right\}$

\subsection{Algorithm}

Step 1. Calculate $D_{1}, D_{2} \& D_{3}$ using (1), (2) \& (3)

Note: In first iteration $\mathrm{D}_{1}=\mathrm{D}_{2}=\mathrm{D}_{3}$

Step 2. Calculate $r_{1}, r_{2} \& r_{3}$ using (4). Using (5) calculate $\mathrm{q} 1, \mathrm{q} 2 \& \mathrm{q} 3$

Step 3. Using these $q_{1}, q_{2} \& q_{3}$ and $\left(X_{1}, Y_{1}\right),\left(X_{2}, Y_{2}\right)$ \& $\left(\mathrm{X}_{3}, \mathrm{Y}_{3}\right)$ calculate $\left(\mathrm{x}_{12}, \mathrm{y}_{12},\right),\left(\mathrm{x}_{23}, \mathrm{y}_{23},\right) \&\left(\mathrm{x}_{31}\right.$, $\mathrm{y}_{31}$,) as given in (6)

Step 4. Update $d_{1}, d_{2}$ and $d_{3}$ using (7)

Step 5. Update $\left(\mathrm{x}_{12}, \mathrm{y}_{12},\right),\left(\mathrm{x}_{23}, \mathrm{y}_{23},\right) \&\left(\mathrm{x}_{31}, \mathrm{y}_{31},\right)$ as $\left(\mathrm{X}_{1}\right.$, $\left.\mathrm{Y}_{1}\right),\left(\mathrm{X}_{2}, \mathrm{Y}_{2}\right) \&\left(\mathrm{X}_{3}, \mathrm{Y}_{3}\right)$

Step 6. Repeat step 1 using the updated values obtained in step 4 and step 5 till $\mathrm{x}_{12} \sim \mathrm{x}_{23} \sim \mathrm{x}_{31}$ and $\mathrm{y}_{12} \sim \mathrm{y}_{23} \sim \mathrm{y}_{31}$

Step 7. Calculate (X, Y) using below formulas

$$
X=\frac{x_{12}+x_{23}+x_{31}}{3} \text { and } Y=\frac{y_{12}+y_{23}+y_{31}}{3}
$$

\subsection{Polynomial fitting algorithm}

RSSI values received from each AP are converted into distance using this algorithm. The signal propagation model which is most used is log-normal shadowing model [14]:

$\mathrm{P}(\mathrm{d})_{\mathrm{dBm}}=\mathrm{P}\left(\mathrm{d}_{0}\right)_{\mathrm{dBm}}-10 \mathrm{nlog}\left(\frac{\mathrm{d}}{\mathrm{d}_{0}}\right)+\mathrm{X}_{0}$

Where, $P\left(d_{0}\right)$ is the path loss at distance of $d_{0}$ meters. $d_{0}$ value is assumed to be $1 \mathrm{~m}$, and $n$ is the path loss exponent. $\mathrm{X}_{0}$ is the RSSI measurement noise. This model cannot characterize RSSI data and distance relationship [13] 
Because of the different indoor environment, to fit various situations various indoor wireless signal transmission models are adopted, a set of some indoor data is measured in the paper and corresponding wireless transmission model is found which improve the precision of the following localization calculation.

Polynomial fitting can be defined as [3]

$d=f(P)=\alpha_{0}+\alpha_{1} P+\alpha_{2} P^{2}+. .+P^{m}+\omega$

Where, $\mathrm{P}$ is the received signal strength, $\mathrm{d}$ is the distance between the transmitter and receiver, $\alpha=\left[\alpha_{0}, \alpha_{1}, \ldots, \alpha_{\mathrm{m}}\right]^{\mathrm{T}}$ is the fitting coefficient. $m$ is the polynomial fitting order which is taken as 3 in our paper. Its calculation is given in [3].

The ith measurement is for $\mathrm{i}=1 \ldots \mathrm{n}$ :

$d_{i}=f_{i}\left(P_{i}\right)=\alpha_{0}+\alpha_{1} P_{i}+\alpha_{2} P_{i}^{2}+. .+\alpha_{m} P_{i}^{2}+\omega_{i}$

Least square estimation of $\hat{\alpha}$ with least errors is as follows

$\hat{\alpha}=\left(P^{T} P\right)^{-1} P^{T} D$

Where,

$D=\left[d_{1}, d_{2}, \ldots, d_{n}\right]^{T}$,

$\mathrm{P}=\left[\begin{array}{cccc}1 & P_{1} & \ldots & P_{1}^{m} \\ 1 & P_{2} & \ldots & P_{2}^{m} \\ \vdots & \vdots & \vdots & \vdots \\ 1 & P_{n} & \ldots & P_{n}^{m}\end{array}\right]$

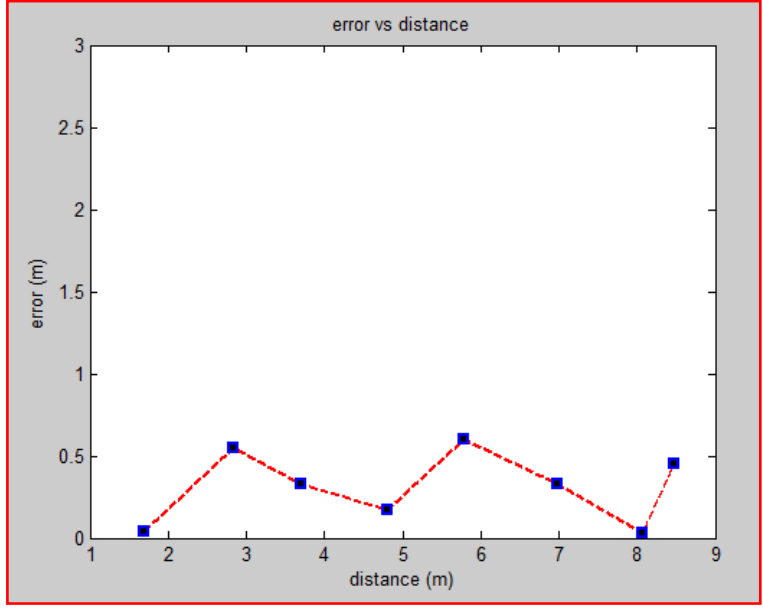

Figure 3. Measured distance error versus distance

Accuracy and error using this polynomial fitting algorithm is given in Fig. 3 which is less than $0.5 \mathrm{~m}$

\section{VHDL DESIGN}

The proposed design is described in VHDL language using IEEE-754 floating point representation. IEEE-754 representation is used to represent the floating point number in binary format. There are three formats

1) Half precision (16 bit)

2) Single precision (32 bit)

3) Double precision (64 bit)

In our design we used single precision format because of its high accuracy compared to half precision and less hardware is required than double precision. Sign bit, number of exponent bits, mantissa bits, precision are given in [16].

\section{RESULTS}

Experiments are carried out to take RSSI measurements using d-link Wi-Fi adapter and NetStumbler software [15].

Table 1 shows the results of the GLA using empirical values of $d_{1}, d_{2}$ and $d_{3}$. The error obtained using empirical values of $\mathrm{d}_{1}, \mathrm{~d}_{2}$ and $\mathrm{d}_{3}$ is $0.062 \mathrm{~m}$.

Table I. Position estimation using actual $d_{1}, d_{2}$ and $d_{3}$

\begin{tabular}{|c|c|c|c|c|c|c|c|}
\hline $\begin{array}{l}\mathrm{X}_{\text {actual }} \\
\text { (meter) }\end{array}$ & $\begin{array}{l}Y_{\text {actual }} \\
\text { (meter) }\end{array}$ & $\begin{array}{l}\mathrm{d} 1_{\text {actual }} \\
\text { (meter) }\end{array}$ & $\begin{array}{l}\mathrm{d} 2_{\text {actual }} \\
\text { (meter) }\end{array}$ & $\begin{array}{c}\mathrm{d} 3_{\text {actual }} \\
\text { (meter) }\end{array}$ & $\begin{array}{c}\mathrm{X}_{\text {estimated }} \\
\text { (meter) }\end{array}$ & $\begin{array}{c}Y_{\text {estimated }} \\
\text { (meter) }\end{array}$ & $\begin{array}{l}\text { Error } \\
\text { (meter) }\end{array}$ \\
\hline 2 & 1 & 2.23 & 8.06 & 8.26 & 2.00 & 0.91 & 0.09 \\
\hline 3 & 2 & 3.61 & 7.28 & 6.99 & 3.00 & 1.92 & 0.08 \\
\hline 4 & 3 & 5.00 & 6.70 & 5.78 & 4.01 & 2.94 & 0.07 \\
\hline 4 & 4 & 5.65 & 7.21 & 4.80 & 3.99 & 3.95 & 0.06 \\
\hline 5 & 5 & 7.07 & 7.07 & 3.70 & 5.00 & 4.96 & 0.04 \\
\hline 5 & 7 & 8.60 & 8.60 & 1.70 & 5.00 & 6.98 & 0.02 \\
\hline 6 & 6 & 8.48 & 7.20 & 2.88 & 6.00 & 5.96 & 0.04 \\
\hline 6 & 4 & 7.20 & 5.65 & 4.80 & 5.99 & 3.94 & 0.07 \\
\hline 7 & 3 & 7.62 & 4.24 & 6.04 & 7.00 & 2.94 & 0.06 \\
\hline 8 & 2 & 8.24 & 2.83 & 7.34 & 7.99 & 1.92 & 0.09 \\
\hline
\end{tabular}


Table II. Comparison of MS coordinates, $(\mathrm{X}, \mathrm{Y})$ obtained by experimental values with actual values

\begin{tabular}{|c|c|c|c|c|c|c|c|}
\hline \multirow[b]{2}{*}{$\begin{array}{l}\mathrm{X}_{\text {actual }} \\
\text { (meter) }\end{array}$} & \multirow[b]{2}{*}{$\begin{array}{l}Y_{\text {actual }} \\
\text { (meter) }\end{array}$} & \multicolumn{3}{|c|}{ Using MATLAB } & \multicolumn{3}{|c|}{ Using VHDL } \\
\hline & & $\begin{array}{c}\mathrm{X}_{\text {est }} \\
\text { (meter) }\end{array}$ & $\begin{array}{c}\mathrm{Y}_{\text {est }} \\
\text { (meter) }\end{array}$ & $\begin{array}{l}\text { Localization } \\
\text { Error (LE1) } \\
\text { (meter) }\end{array}$ & $\begin{array}{c}\mathrm{X}_{\text {est }} \\
\text { (meter) }\end{array}$ & $\begin{array}{c}\mathrm{Y}_{\text {est }} \\
\text { (meter) }\end{array}$ & $\begin{array}{l}\text { Localization } \\
\text { Error (LE2) } \\
\text { (meter) }\end{array}$ \\
\hline 2 & 1 & 2.16246998 & 1.19683866 & 0.2552 & 2.16246986 & 1.19684374 & 0.2552 \\
\hline 3 & 2 & 2.49641364 & 2.13423568 & 0.5212 & 2.48765873 & 2.13423776 & 0.5296 \\
\hline 4 & 3 & 4.25721245 & 3.35509385 & 0.4385 & 4.25720453 & 3.35509967 & 0.4385 \\
\hline 4 & 4 & 3.61956190 & 4.16909936 & 0.4163 & 3.61956095 & 4.16910266 & 0.4163 \\
\hline 5 & 5 & 4.99999999 & 5.52574095 & 0.5257 & 5.00000238 & 5.52574682 & 0.5257 \\
\hline 5 & 7 & 5.00000000 & 6.38348530 & 0.6165 & 5.00000572 & 6.38327374 & 0.6167 \\
\hline 6 & 6 & 5.50543779 & 6.13979977 & 0.5139 & 5.50543403 & 6.13981294 & 0.5139 \\
\hline 6 & 4 & 6.38043809 & 4.16909936 & 0.4163 & 6.38044357 & 4.16910289 & 0.4163 \\
\hline 7 & 3 & 7.51400680 & 2.41908622 & 0.7757 & 7.51407194 & 2.41908931 & 0.7757 \\
\hline 8 & 2 & 8.04988319 & 1.62541659 & 0.3779 & 8.04988479 & 1.62541341 & 0.3779 \\
\hline & & & Mean & .4857 & & Mean $=$ & 4866 \\
\hline
\end{tabular}

Table 2 shows the comparison of $(\mathrm{X}, \mathrm{Y})$ coordinates values i.e., actual coordinates, values obtained by

MATLAB implementation and values obtained by VHDL implementation. It also gives the localization error (LE), which is the distance between actual coordinates and estimated coordinates. LE 1 and LE2 are the localization errors with respect to actual coordinates and coordinates obtained by MATLAB and VHDL. These are given by (8) and (9) respectively

$$
\begin{aligned}
\mathrm{LE} 1 & =\sqrt{\left(\mathrm{X}_{\mathrm{act}}-\mathrm{X}_{\mathrm{MAT}}\right)^{2}+\left(\mathrm{Y}_{\mathrm{act}}-\mathrm{Y}_{\mathrm{MAT}}\right)^{2}} \\
\mathrm{LE} 2 & =\sqrt{\left(\mathrm{X}_{\mathrm{act}}-\mathrm{X}_{\mathrm{VHDL}}\right)^{2}+\left(\mathrm{Y}_{\mathrm{act}}-\mathrm{Y}_{\mathrm{VHDL}}\right)^{2}}
\end{aligned}
$$

From the table we can observe that, LE1 is $0.4857 \mathrm{~m}$ and LE2 is $0.4866 \mathrm{~m}$.

\subsection{MatLab simulations}

Simulations are carried out by taking the APs locations as follows: $\mathrm{AP}_{1} \mathrm{AP}_{2}, \mathrm{AP}_{2} \mathrm{AP}_{3}$

$\mathrm{AP}_{1^{-}}\left(\mathrm{X}_{1}, \mathrm{Y}_{1}\right)=(0,0)$

$\mathrm{AP}_{2}-\left(\mathrm{X}_{2}, \mathrm{Y}_{2}\right)=(10,5)$

$\mathrm{AP}_{3}-\left(\mathrm{X}_{3}, \mathrm{Y}_{3}\right)=(5,8.6)$

The above simulation is carried out for 8 iterations and then we find that results converge to the actual values. Variation of the $\mathrm{X}$-coordinates, $\mathrm{x}_{12}, \mathrm{x}_{23}$ and $\mathrm{x}_{31}, \mathrm{Y}$-coordinates $\mathrm{y}_{12}, \mathrm{y}_{23}$ and $y_{31}$ and average of these values i.e., $(X, Y)$ in every iteration are given in Fig.4, Fig.5 and Fig.6 respectively

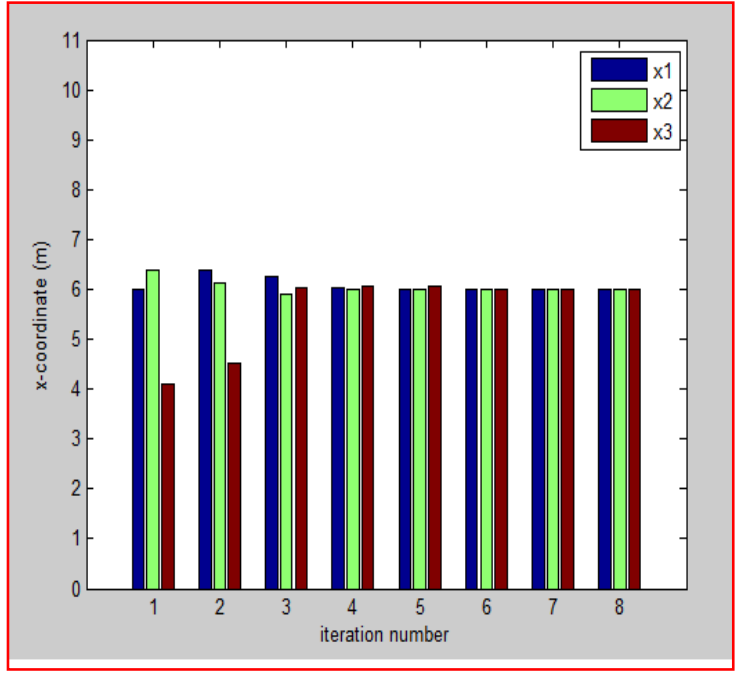

Figure 4. Variation of $\mathrm{x}$-coordinates with iteration number

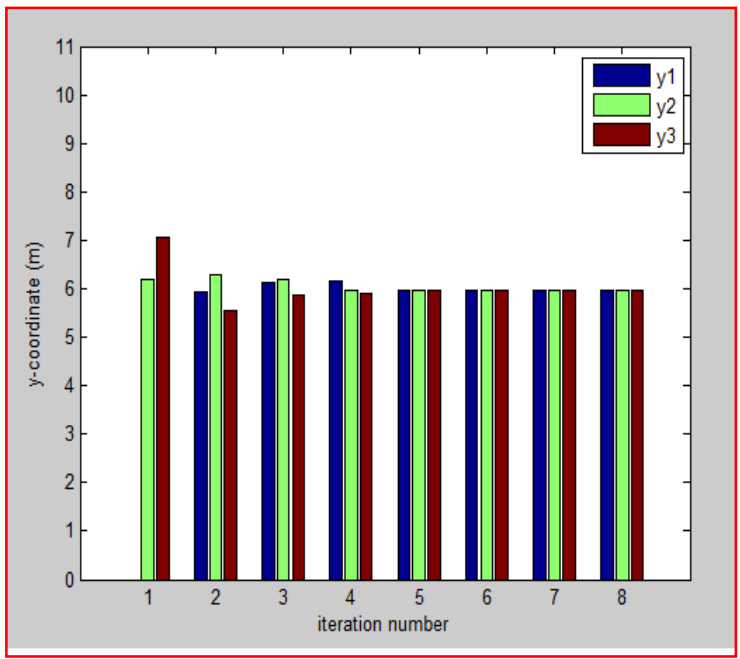

Figure 5. Variation of y-coordinates with iteration number 


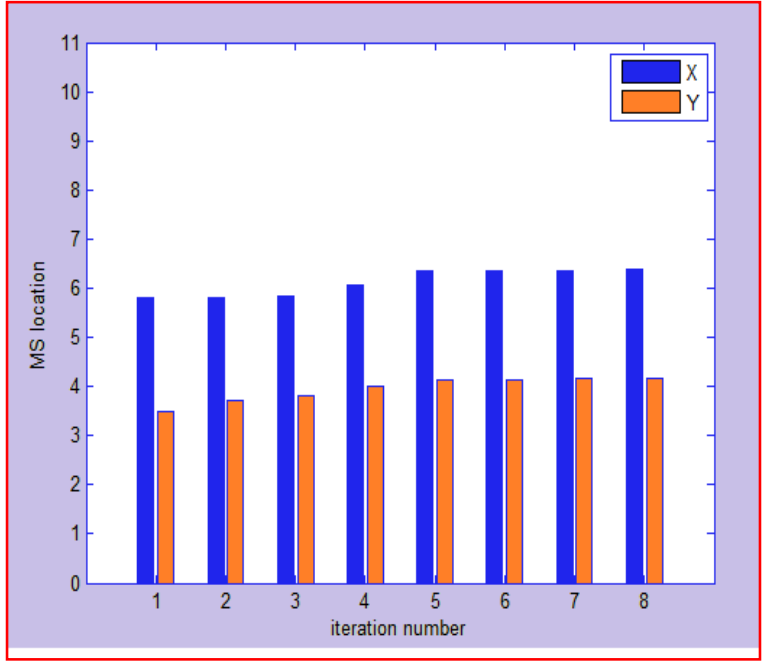

Figure 6. Variation of $(X, Y)$ with iteration number

\subsection{VHDL results}

VHDL Implementation of GLA using IEEE754 32-bit single precision floating point representation is given in this section.

The proposed design is synthesized at RTL level using XILINX ISE 10.1 software targeted to the device $5 \mathrm{vlx} 110 \mathrm{tff} 1738$ with speed grade of -2 . Top module is shown in Fig.7 and RTL schematic of GLA is shown in Fig.8

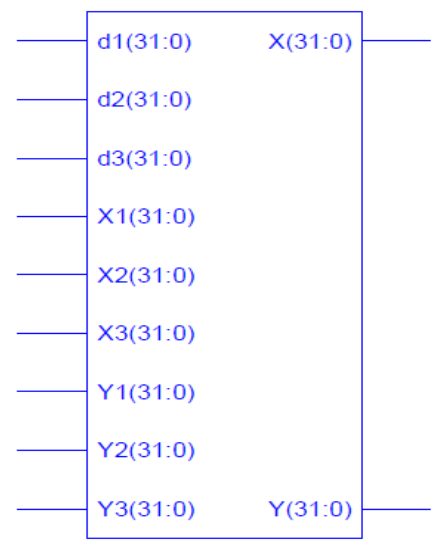

Figure 7. Top level RTL schematic

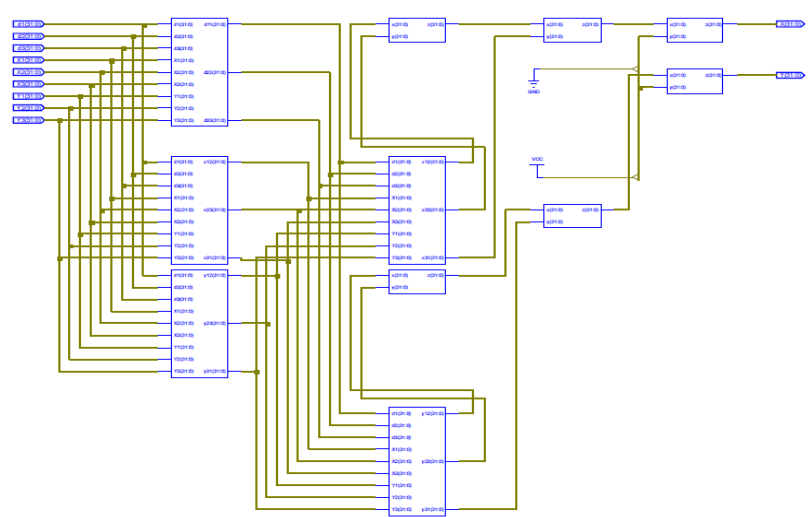

Figure 8. RTL schematic of GLA

Fig.9 shows the VHDL simulation of our positioning technique for MS coordinate values $(6,4)$, Expected values of $(\mathrm{X}, \mathrm{Y})$ are $(6.38043809,4.16909936)$, and obtained values of $(\mathrm{X}, \mathrm{Y})$ using VHDL simulation are (6.38044357,
4.16910289). Error obtained is (0.00000548, 0.00000353). Simulations are carried out using ISE simulator.

Device utilization summary of the synthesis process is given in table 3

Table III. Device utilization summary

\begin{tabular}{|c|r|r|r|}
\hline \multicolumn{4}{|c|}{ Device Utilization Summary (estimated values) } \\
\hline \multicolumn{1}{|c|}{ Logic Utilization } & Used & Available & Utilization \\
\hline Number of Slice LUTs & 29421 & 69120 & $42 \%$ \\
\hline $\begin{array}{l}\text { Number of fully used } \\
\text { LUT-FF pairs }\end{array}$ & 0 & 29421 & $0 \%$ \\
\hline $\begin{array}{l}\text { Number of bonded } \\
\text { IOBs }\end{array}$ & 381 & 680 & $56 \%$ \\
\hline \begin{tabular}{l} 
Number of DSP48Es \\
\hline
\end{tabular} & 54 & 64 & $84 \%$ \\
\hline
\end{tabular}

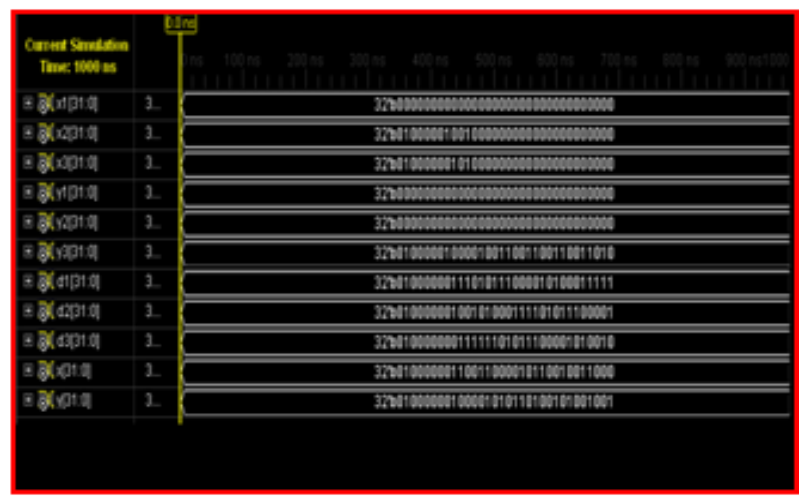

Figure 9. Simulation of GLA

\section{CONCLUSION}

Proposed location algorithm provides accurate WLAN positioning technique. Real time RSSI values are used to obtain the position of the MS from set of distance estimations to the access points. We have compared localization error through numerical simulations and real experiments. Accurate results are obtained. Comparisons of the MS coordinates obtained by MATLAB and VHDL with actual coordinates are presented.

The system is tested and validated in MATLAB and is described in VHDL language using XILINX ISE10.1 tool and is simulated using ISE simulator. IEEE-754 single precision floating point representation is used, which increases the accuracy of the positioning system. The technique could be extended to WLANs in other environments such as office, auditorium and industry.

\section{REFERENCES}

[1] P. Enge and P. Misra. Special issue on GPS: The Global Positioning System. Proceedings of the IEEE, pages 3172, January 1999.

[2] ZAIDI, OUNI, Bhar and TOURKI," A Novel Positioning Technique with Low Complexity in Wireless LAN: Hardware Implementation" Proceedings of the World Congress on Engineering 2011 Volume II WCE 2011, July 6 - 8, 2011, London, U.K. 
[3] Long Cheng, Cheng-Dong Wu and Yun-Zhou Zhang," Indoor Robot Localization Based on Wireless Sensor Networks", IEEE Transactions on Consumer Electronics, Vol. 57, No. 3, August 2011

[4] I. Jami, M. Ali, R.F. Ormondroyd, Comparison of Methods of Locating and Tracking Cellular Mobiles, Novel Methods of Location and Tracking of Cellular Mobiles and Their System Applications (Ref. No.1999/046), IEE Colloquium, London UK,1/1-1/6.

[5] Y.T. Chan, K.C. Ho," A simple and efficient estimator for hyperbolic location", IEEE Transactions on Signal Processing, 42(8) (1994).

[6] Alba Pages-Zamora, Josep Vidal, Dana H. Brooks," Closed-form solution for positioning based on angle of arrival measurements", in: Proc. of the 13th Sym. on Personal, Indoor and Mobile Radio Communications, September 2002, vol. 4, pp. 1522-1526.

[7] Dinesh Sharma, Purnima K Sharma, Vishal Gupta, and R.K Singh4," A Survey on Path Loss Models Used In Wireless Communication System Design", International J. of Recent Trends in Engineering and Technology, Vol. 3, No. 2, May 2010

[8] M. Hata, "Empirical formula for propagation loss in land mobile radio services," IEEE Trans. Vehic. Technol., Vol VT-29, No. 3, pp. 317-325, Aug. 1980.

[9] COST action 231 digital mobile radio towards future generation systems final report," tech. r ep., European Communities, EUR 18957, 1999
[10] Phillip A. Thomas, Sylvester M. Nabritt, Dr.Madjid A.Belkerdid" Propagation Models used in Wireless Communications System Design" IEEE 1998.

[11] Y. Zhao, Standardization of mobile phone positioning for 3G systems, IEEE Communications Magazine 40 (4) (2002) 108-116

[12] Chi-Kuang Hwang and Kun-Feng Cheng "Wi-Fi Indoor Location Based on RSS Hyper-Planes Method," Chung Hua Journal of Science and Engineering, Vol. 5, No. 4, pp. 37-43 (2007)

[13] Patwari, N., Hero, A.O., III, Perkins, M., Correal, N.S., O'Dea, R.J., "Relative location estimation in wireless sensor networks," IEEE Trans. On Signal Processing. Vol.51 No.8, pp.2137-2148, Aug.2003.

[14] Saxena M., Gupta P., Jain B.N., "Experimental analysis of RSSI-based location estimation in wireless sensor networks," COMSWA, 2008, pp.503-510.

[15] M. Milner. Network stumbler version 0.4.0 NetStumbler; www.netstumbler.com, 2001-2004

[16] Yen-Chang Huang, Pei-Ju Lin, Yu-Jung Huang, and Ming-Dou Ker," CORDIC Implementation of RSSI Localization Method", IEEE transaction on Microelectronics and Electronics (PrimeAsia), 2010 Asia Pacific Conference on Postgraduate Research in 2010 , Page(s): $295-298$ 